\title{
FACT-CHECKING: UMA ANÁlise DA CHECAGEM DE INFORMAÇÃo POLÍTICA DO PROJETO TRUCO!
}

\author{
Desirèe Luise Lopes CONCEIÇÃO* \\ Rosemary SEGURADO**
}

RESUMO: O artigo tem por objetivo analisar a produção e divulgação de informação política na plataforma digital Truco!, um projeto de fact-checking checagem de informação - da Agência Pública desenvolvido para as eleições 2014. A iniciativa, uma das pioneiras no Brasil, levantava discursos dos candidatos à presidência no Horário Gratuito de Propaganda Eleitoral (HGPE) na televisão e verificava as declarações comparando-as com dados disponíveis. A conclusão da verificação, publicada na internet, revelava se as falas continham informações corretas, sem contexto, distorcidas ou falsas. A metodologia consistiu na elaboração de indicadores para coleta de dados primários e entrevistas individuais. Os resultados permitem identificar um trabalho de jornalismo investigativo de qualidade, revelando um processo para a checagem e a ampliação do conteúdo político sobre temáticas surgidas no HGPE. Assim, construiu-se um espaço de contrainformação, com possibilidade de pensar a prática de checagem para fazer frente a um fenômeno recente, os casos de fake news - notícias falsas.

PALAVRAS-CHAVE: Internet. Discurso político. Ciberpolítica. Fact-checking. Checagem de informação.

PUC-SP - Pontifícia Universidade Católica de São Paulo. Programa de Estudos Pós-Graduados em Ciências Sociais e Núcleo de Estudos em Arte, Mídia e Política (Neamp). São Paulo - SP - Brasil. 05015-901 - deluise19@gmail.com. https://orcid.org/0000-0002-2700-3864

* PUC-SP - Pontifícia Universidade Católica de São Paulo. Programa de Estudos Pós-Graduados em Ciências Sociais e Núcleo de Estudos em Arte, Mídia e Política (Neamp). São Paulo - SP - Brasil. 05015-901 - roseseg@uol.com.br. https://orcid.org/0000-0002-3910-4603 


\section{Introdução}

O avanço das tecnologias digitais provocou, na sociedade contemporânea, mudanças nos hábitos sociais, como nas formas de sociabilidade e comunicação social. Com a chegada da internet ocorrem transformações nos moldes de produção e divulgação de informação, pois há inserção do "domínio da técnica na esfera do discurso e da comunicação de forma radical, criando novas tensões entre a técnica, por um lado, e a pólis, a política, por outro" (LEMOS; LÉVY, 2010, p.22-23).

A nova conectividade presente com a digitalização do mundo cria possibilidades de ampliação da comunicação, o que deverá gerar efeitos políticos. Neste contexto, está localizada a relação entre a internet e as novas modalidades de jornalismo on-line, que criam possibilidades para "mecanismos de monitoramento público do poder político, especialmente por ocasião dos processos eleitorais e de representação política" (CARVALHO; CERVI; MASSUCHIN, 2016, p.397).

Segundo John Keane (2009, apud CARVALHO; CERVI; MASSUCHIN, 2016), há uma tendência cada vez maior de acontecer, principalmente durante as eleições, um escrutínio público do sistema político por parte da esfera civil, em decorrência do desenvolvimento das Tecnologias da Informação e Comunicação (TICs). Nesse sentido, ainda de acordo com o autor, as tecnologias digitais provocam uma alteração na democracia representativa, podendo essa ser caracterizada com o que chamou de democracia monitorada, pela criação de instrumentos de monitoramento do sistema político e seus atores.

Em especial nas eleições de 2014 no Brasil, surgiram mais expressivamente sites, plataformas e aplicativos para celular destinados aos cidadãos que almejassem saber mais sobre os candidatos aos cargos públicos do Executivo e Legislativo. A pretensão desses dispositivos, em geral, era a de contribuir com informações para que a população obtivesse mais elementos na hora de decidir sobre o voto. Também com esse intuito, o projeto de fact-checking - checagem de informação, na tradução livre - Truco! $!^{1}$ chamou a atenção da mídia por sua proposta inovadora, obtendo à época mais de 80 menções em veículos tradicionais da imprensa como TV Brasil, CBN, TV Cultura, BBC, Globonews e Rádio Jovem Pan².

Podendo ser simultaneamente tipificado como prática cibercultural e jornalística, o projeto Truco! foi desenvolvido pela Agência Pública ${ }^{3}$ com a preocupação de trabalhar com uma nova abordagem de cobertura política. A

\footnotetext{
1 Disponível em apublica.org/truco2014/. Acesso em: 3 abr. 2018.

2 Contabilização realizada pela Agência Pública e divulgada no texto "Um turbilhão de trucos", disponível em apublica.org/2014/11/um-turbilhao-de-trucos/. Acesso em: 18 jun. 2019.

3 Iniciativa de mídia independente - não atrelada a um veículo comercial. Produz conteúdo com base no jornalismo investigativo, com propósito de fortalecer o direito à informação e a promoção dos direitos humanos e qualificar o debate democrático. Disponível em: apublica.org/quem-somos/. Acesso em: 9 abr. 2018.
} 
iniciativa de fact-checking teve como finalidade central verificar o discurso dos candidatos à presidência em 2014, confrontando suas declarações com fatos e dados disponíveis. O resultado dessa investigação da Pública revelava se o discurso dos políticos, especificamente durante o Horário Gratuito de Propaganda Eleitoral (HGPE) na televisão, era verdadeiro, sem contexto, contraditório, discutível, distorcido, exagerado ou falso.

Um dos primeiros projetos de fact-checking no Brasil, o Truco! foi lançado em agosto de 2014, mês em que iniciou a campanha eleitoral na TV. Para o mesmo pleito, o jornal O Globo criou o Preto no Branco, blog de checagem dos discursos políticos que se tornou inativo a partir do ano seguinte. Posteriormente às eleições daquele ano, a plataforma Aos Fatos foi lançada apenas em julho de 2015, como iniciativa independente assim como o projeto da Pública. Já A Lupa começou suas atividades, em novembro do mesmo ano, como parte do site da revista Piauí, no modelo de startup, totalizando três projetos de checagem de informação ativos no Brasil até 2017.

O lançamento do Truco! faz parte de um fenômeno global de surgimento de iniciativas de checagem, que entende a verificação de discursos públicos como atividade importante para a informação de qualidade na democracia (CONCEIÇÃO, 2018b). O projeto brasileiro foi inspirado no argentino Chequeado (ato de verificar, tradução nossa), criado em 2010 e primeiro do tipo na América Latina. Existem ainda nos Estados Unidos, desde 2003, o FactCheck.org; o Polifact, desde 2005, também estadunidense; Del Dicho al Hecho (Do Dito ao Feito, tradução nossa), lançado em 2014 no Chile; o site sul-africano AfricaCheck desde 2012; e o Pagella Política (Boletim Político, tradução nossa) na Itália, também de 2012, para mencionar exemplos.

Apesar de um fenômeno relativamente novo, o número de iniciativas de fact-checking no mundo tem aumentado todos os anos, desde o início da série histórica de mapeamento, em 2014 (STENCEL, 2019). O levantamento, representado no gráfico 1, com o mês de corte fevereiro do ano, é do Duke Reporters Lab ${ }^{4}$, que monitora plataformas dessa natureza. As iniciativas localizadas em diversos países têm em comum o intuito de averiguar o discurso público, ou as declarações dos políticos; serem desenvolvidas como plataformas digitais; e o trabalho adotar como base o jornalismo investigativo (CONCEIÇÃO, 2018b).

\footnotetext{
4 Laboratório de repórteres situado na Duke University, localizada em Durham, na Carolina do Norte (EUA). Tem como premissa explorar novas formas de jornalismo, incluindo a checagem de informação, segundo o site sobre o laboratório. Disponível em: reporterslab.org/about-the-lab/. Acesso em: 8 abr. 2018.
} 
Gráfico 1 - Projetos de fact-checking ativos no mundo

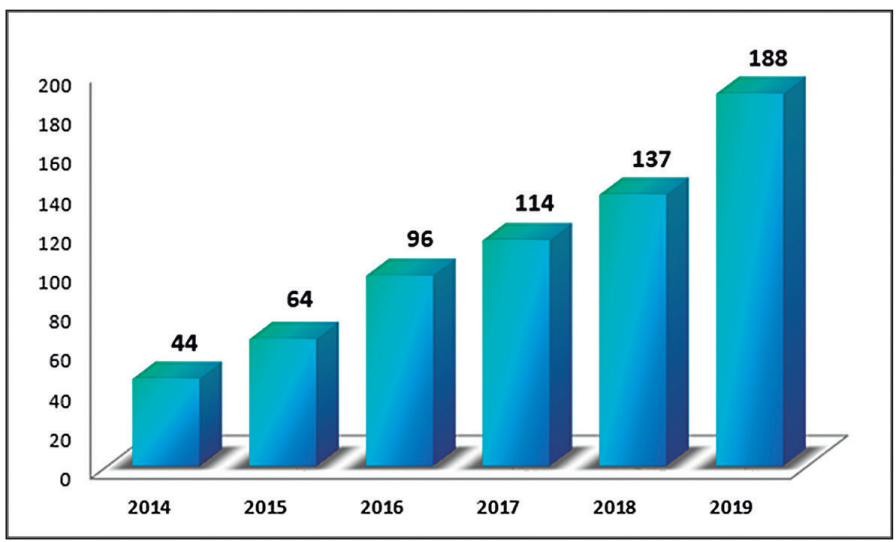

Fonte: autora

Outro ponto a observar é que o trabalho desenvolvido na checagem se relaciona com um contexto que têm se apresentado nos últimos anos, o do crescimento de casos de fake news ${ }^{5}$ nas redes digitais que têm favorecido o que se pode chamar de desinformação. As redes permitem a circulação de quantidade cada vez maior de conteúdos tornando as informações mais acessíveis, mas também esse ambiente favoreceu a proliferação de notícias falsas, que encontrou um território livre para reverberar principalmente nas redes sociais digitais.

Diante da elevação da presença das fake news, os projetos de fact-checking passaram a ampliar seu campo de atuação: de especificamente verificação de discursos dos políticos, e candidatos aos pleitos, para informações possivelmente inverídicas que passaram a circular no meio on-line. Informações essas também associadas à política, com constância maior desde as eleições presidenciais de 2016 nos Estados Unidos, envolvendo, em especial, o então candidato republicano Donald Trump.

Também em 2016, no referendo do Brexit, a campanha que resultou na escolha pela saída do Reino Unido da União Europeia foi marcada pela circulação de fake news, no campo econômico sobre valores a ganhar ou perder com a decisão, bem como em relação a imigrantes roubando empregos de locais. Ainda, nas eleições no Brasil, dois anos depois, em 2018, foi possível identificar ondas de notícias falsas e a campanha eleitoral do atual presidente Jair Bolsonaro foi beneficiada por isso, como mostra a reportagem do jornal britânico The Guardian, de 30 de outubro de 2019 (AVELAR, 2019). O gerente do WhatsApp, Ben Supple, chegou a admitir que a plataforma esperava que haveria desinformação: "Sempre soubemos

5 Da tradução notícia falsa. Para este trabalho, adota-se como notícias e informações produzidas intencionalmente e comprovadamente falsas. 
que as eleições brasileiras seriam um desafio. Era uma eleição muito polarizada e as condições eram ideais para a disseminação de desinformação" (MELLO, 2019).

Assim, uma iniciativa pioneira no Brasil realizada por um veículo de mídia independente, a plataforma digital Truco! será o objeto de análise desta pesquisa como um estudo de caso. Considera-se relevante a prática de checagem ainda ser pouco estudada em pesquisas acadêmicas brasileiras, portanto ainda com vasto campo científico a ser percorrido, e também o trabalho de verificação ser sobre discursos políticos, ao considerar que a política é um campo de batalha na qual ocorre uma guerra simbólica, e o discurso político cumprir papel essencial nesse processo ao atuar para influenciar opiniões, objetivando obter adesões às propostas que defende, ou rejeições aos projetos adversários (CHARAUDEAU, 2011 apud CIOCCARI; COELHO; EZEQUIEL, 2019).

O objetivo deste artigo é o de avaliar a produção e divulgação de informação política, durante as eleições de 2014, na plataforma digital Truco! que acontecia por meio da prática do fact-checking. Observando, assim, a qualidade do processo de checagem de informação em relação aos discursos dos políticos durante o HGPE para, em um segundo momento, entender suas potencialidades em um contexto de redes digitais.

\section{Metodologia}

Primeiramente, considera-se importante explicitar como a checagem de informação ocorria - o que explica o nome do projeto -, os critérios e processos para sua realização, bem como a viabilidade econômica que permitiu a sustentabilidade da Agência Pública, contidos nos tópicos 2 e 3 deste trabalho. O aprofundamento da compreensão sobre o funcionamento do Truco! foi viabilizado a partir de entrevistas individuais com um dos três editores do projeto à época, Maurício Moraes ${ }^{6}$, que ajudou a elaborar e organizar a iniciativa.

Depois, no tópico 4 deste artigo, adentra-se nos resultados empíricos da avaliação realizada sobre a checagem de informação do projeto Truco! Para averiguar a informação produzida e divulgada por meio do fact-checking, indicadores foram elaborados a partir de uma análise piloto da edição 1 de checagem de informação da Pública, de 19 de agosto de $2014^{7}$. A construção dos indicadores possibilitou a coleta de dados primários objetivando avaliações qualitativas.

\footnotetext{
6 Formado em jornalismo (1997) e história (2015) pela Universidade de São Paulo (USP), começou a trabalhar como jornalista em 1998. Na Pública, entrou como editor em agosto de 2013. Ocupou especificamente a função de editor de fact-checking da agência de agosto de 2015 a novembro de 2018. 7 TRUCO! PROGRAMA \#1 - 19 de agosto de 2014. Disponível em: apublica.org/truco-programa-1/. Acesso em: 10 out. 2017.
} 
Assim, o corpus de análise ficou composto por todas as 33 edições de checagem que a agência publicou em sua plataforma na internet, entre os dias 19 de agosto e 24 de outubro de 2014, quando perdurou o horário eleitoral na televisão. A partir de todas as edições publicadas, foram levantados 98 discursos checados pela Pública que são avaliados para este estudo a partir de três indicadores.

Com o primeiro, denominado Critérios, pretendeu-se apreender se os discursos verificados pela Pública estavam enquadrados nos critérios a que a agência se propôs inicialmente para elencar essas falas. O segundo indicador, Recursos, identificou a presença do suporte utilizado pela agência em seus textos argumentativos para justificar a classificação que fazia dos discursos políticos. Além de Coerência, que averiguou se havia correspondência entre o resultado da checagem (uso de cartas, a serem explicadas a seguir) e a argumentação da Pública para sustentar tal veredicto por meio dos textos argumentativos.

\section{Processo de verificação dos discursos políticos}

Em relação à dinâmica da checagem, após cada programa do HGPE no ar, a equipe da Agência Pública averiguava as informações contidas nas declarações dos candidatos à presidência e distribuía cartas de baralho (validações) correspondentes para cada determinada fala dos políticos, com o intuito de demonstrar até que ponto o que diziam na propaganda era factível, se o contexto correto mudaria a informação, ou se o que dizia o presidenciável era uma inverdade.

Assim como no jogo de baralho Truco, e justificando o nome e a dinâmica adotados para o projeto, cartas eram utilizadas para apontar qual foi a conclusão sobre o discurso do político avaliado, após a averiguação da sustentabilidade da informação realizada pela equipe do projeto. Para isso, a Pública criou um padrão de cartas, definindo os significados de cada uma, como descritos a seguir:

- Não é Bem Assim - Informação exagerada, distorcida ou discutível;

- Tá Certo, Mas Pera aí - Informação correta, mas que merecia ser contextualizada. Existiriam mais dados que o eleitor precisaria saber além dos apresentados no programa eleitoral;

- Blefe! - A informação era falsa. Dados de outras fontes foram usados, além do auxílio de especialistas, para confrontar a versão apresentada pelo candidato;

- Zap! - Informação correta e relevante dita pelo político. Para demonstrar isso, foram apresentados números que confirmariam e ampliariam a declaração; 
- Truco! - Informação insustentável e promessa grandiosa, sem explicação de como seria implementada.

Também, no segundo turno, foram criadas três cartas novas: Candidato em Crise quando havia uma contradição com algo dito anteriormente, Carta Marcada quando a mesma afirmação questionável já fora usada no primeiro turno; além de Que Medo! quando a Pública se posicionava discordando dos candidatos quanto às propostas que, na concepção do veículo, eram perigosas para a democracia e os direitos humanos.

Os momentos de aplicação da carta Truco! configuraram uma dinâmica diferenciada e não compõem material para as análises deste artigo, pois não se trata da prática de checagem de informação. Isso porque nos casos da carta Truco! a Agência Pública estabelecia contato com as campanhas dos presidenciáveis, enviando perguntas relacionadas à declaração do candidato. A ação correspondeu a um desafio público para que explicassem afirmações ou promessas aparentemente insustentáveis. As respostas obtidas eram divulgadas também dentro da iniciativa on-line.

As checagens dos discursos dos candidatos eram publicadas em formato de edições na internet. Cada programa eleitoral que foi ao ar na televisão correspondia a uma edição de checagem divulgada na plataforma on-line. Assim, tomando como exemplo o $27^{\circ} \mathrm{HGPE}$ que foi ao ar em 17 de outubro de 2014, tem-se como resultado a $27^{\mathrm{a}}$ edição de checagem, composta por quatro discursos averiguados ${ }^{8}$. Cada discurso era publicado na plataforma Truco! juntamente com a carta que trazia o resultado do discurso avaliado (imagem 1), e com um texto argumentativo, que explicava o porquê aquela declaração foi classificada com a determinada carta (imagem 2).

No exemplo das imagens 1 e 2 a seguir, o candidato Aécio Neves (PSDB), durante o HGPE de 17 de outubro, no segundo turno das eleições, disse que "o reajuste real do salário mínimo de 2016, por exemplo, já está estabelecido, porque é o crescimento do PIB esse ano: é nada" . A Pública apontou que "o candidato está enganado. Como a Política de Valorização do Salário Mínimo termina em 2015, o reajuste de 2016 dependerá de um novo critério, a ser definido pelo candidato eleito no segundo turno"10.

\footnotetext{
8 Truco! Programa \#27. Agência. Pública, 17 de outubro de 2014. Disponível em: apublica.org/trucoprograma-27/. Acesso em: 24 abr. 2017.

9 Idem.

10 Idem.
} 


\title{
Desirèe Luise Lopes Conceição e Rosemary Segurado
}

Imagem 1: exemplo da carta Blefe! destinada ao discurso do então candidato Aécio Neves, na checagem de 16/10/2014

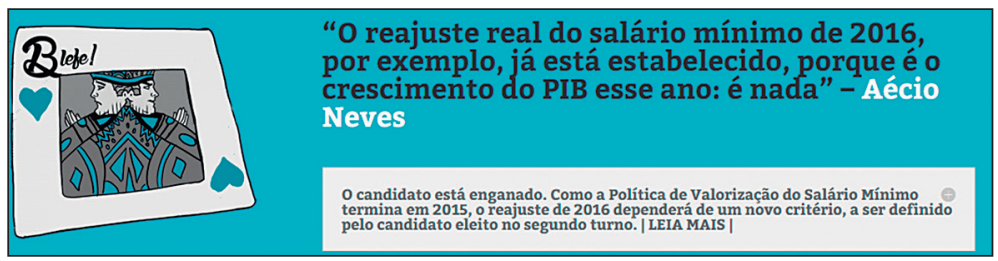

Fonte: Reprodução. Disponível em: apublica.org/truco-programa-27/. Acesso em: 24 abr. 2017

Imagem 2: texto argumentativo que justificou a classificação da checagem do discurso de Aécio Neves com a carta Blefe! em 16/10/2014

\section{o candidato está enganado. Como a Política de Valorização do Salário Mínimo termina em 2015, o reajuste de 2016 dependerá de um novo critério, a ser definido pelo candidato eleito no segundo turno. | LEIA MAIS |}

\begin{abstract}
Os aumentos no salário minimo superiores à inflaçāo começaram no governo Lula, a partir de uma negociação com as centrais sindicais. A regra atual foi definida pela Lei 12.382, de 2011.Segundo a norma, de 2012 a 2015, o indice de correçāo é calculado com a soma de dois porcentuais: o crescimento do Produto Interno Bruto (PIB) de dois anos antes: e a inflaçāo dos 12 meses anteriores ao reajuste, medida pelo İndice Nacional de Preços ao Consumidor (INPC).

A lei também definiu que, atè 31 de dezembro de 2015. o poder Executivo deve encaminhar um novo projeto de lei ao Congresso Nacional com as regras para os reajustes dos próximos anos. Assim, quem for eleito poderá manter o atual modelo, cancelá-lo ou modificá-lo, de acordo com os critérios que achar convenientes.

Um projeto em tramitaçāo no Senado, que mantém as regras vigentes atè 2019. recebeu em agosto parecer favorável da Comissão de Assistência Social. A proposta está agora na Comissāo de Assuntos Econômicos. Ainda não se sabe quando chegará ao plenário, mas dificilmente a aprovaçāo ocorrerá este ano.

Também é cedo para dizer que. se for mantida a regra atual, o aumento real de 2016 será "nada". O crescimento do PIB de 2014 só será conhecido no ano que vem. Atualmente, a previsão oficial feita pelo Ministério do Planejamento é de $0,9 \%$.
\end{abstract}

Fonte: Reprodução. Disponível em: apublica.org/truco-programa-27/. Acesso em: 24 abr. 2017

A equipe da Agência Pública coletou as informações durante o horário eleitoral orientados a partir do pressuposto de que qualquer conteúdo poderia estar distorcido. Ao assistirem o HGPE na televisão, extraíam os discursos em formato de frases para facilitar a posterior averiguação. Porém, as declarações políticas não embasadas em dados ou justificativas possíveis de serem pesquisadas, portanto, passíveis de serem comprovadas, não poderiam ser checadas e foram descartadas pela Pública. Por estarem em um campo além dos fatos, os seguintes casos não foram checados: propostas políticas, afirmações com termos imprecisos (sem citação de dados ou fatos) ou a opinião dos políticos sobre qualquer tema. 
Após essa primeira triagem, do que seria passível ou não de buscar comprovação em fatos e dados por meio de apuração, também houve casos em que a Pública encontrou barreiras para chegar às informações suficientes que possibilitassem realizar determinadas checagens. Geralmente quando havia a necessidade de solicitar dados para órgãos governamentais, as respostas não eram obtidas por falta do solicitado e, assim, também se optou por descartar a fala do político para publicação nas edições de checagem, de acordo com Maurício Moraes (informação verbal) ${ }^{11}$.

Dessa forma, o processo metodológico utilizado pela Agência Pública para realização do fact-checking pode ser resumido da seguinte forma: coleta dos discursos dos presidenciáveis em formato de frases; pesquisa de dados e informações que atestassem ou refutassem a declaração realizada pelo político (apuração); análise verificando se a partir do material obtido seria possível classificar a frase; classificação do discurso por meio das cartas de baralho de acordo com o resultado da checagem de informação, podendo ser em sete categorias: Não é bem assim, Tá certo, mas pera aí, Blefe!, Zap!, Candidato em crise, Carta marcada ou Que medo!; produção de texto com argumentação que justificasse a classificação das cartas; e publicação dos resultados da checagem na plataforma on-line.

Em processo de evolução do trabalho de checagem, a Pública passou a ser auditada em relação à consistência de sua metodologia para figurar entre os signatários de um Código de Princípios - mantido pelo Poynter Institute for Media Studies, um centro de treinamento de mídia localizado em São Petersburgo, Flórida (EUA) -, que atesta a confiabilidade de projetos de fact-checking. O modelo de checagem continua em aprimoramento, assim como fazem outras organizações internacionais do tipo.

O Código de Princípios de checagem de informação foi acordado em 2016 pelo conjunto dos checadores presentes durante o encontro anual Global Fact-Checking Summit (Cúpula Global de Checagem de Informação, tradução nossa), em Buenos Aires, na Argentina (MANTZARLIS, 2016). Criado para consolidar a confiança do público nas plataformas de fact-checking, o instrumento prevê a realização de uma auditoria independente para tornar os projetos aptos a assinarem o documento. A Agência Pública teve a sua auditoria concluída em 28 de março de 2017, tornando-se uma das signatárias (POYNTER, 2017). As outras duas iniciativas brasileiras - A Lupa e Aos Fatos - também assinam.

Calcado em cinco pontos éticos, o Código de Princípios enfatiza um comprometimento dos que assinam o documento com: a imparcialidade e equidade ao realizar as checagens; a transparência das fontes utilizadas para fazer as averiguações

\footnotetext{
11 Informação mencionada por Maurício Moraes durante entrevista presencial para o desenvolvimento desta pesquisa, em São Paulo-SP, em maio de 2017.
} 
dos discursos; a transparência com relação ao financiamento da organização que realiza o projeto de checagem; a transparência na metodologia usada pelo projeto; e a visibilidade no reconhecimento de erros, quando forem realizadas correções no trabalho de checagem (POYNTER, 2017).

Ao observar o produto final de um processo de fact-checking (a informação checada), na comparação com um produto jornalístico tradicional (a notícia), "o jornalismo assume uma nova forma de mediação de caráter mais procedimental, através da rotina de checagem e confrontação de dados, e o fato da declaração ser verdadeira ou falsa se transforma na própria notícia" (DOURADO, 2016, p.18). Assim, o fact-checking poderia ser visto como um incremento da fiscalização da cobertura política realizada pela imprensa tradicional, pois possibilita "transparência das informações políticas, persegue a credibilidade do ator político e, a partir de tudo isso, oferece ao cidadão maior poder de argumentação sobre temas de interesse público" (DOURADO, 2016, p.18).

Por isso, um dos pontos ressaltados é que a prática fact-checking evita o que pode ser denominado de jornalismo declaratório, quando a construção da notícia acontece a partir de informações do tipo "ele disse, ela disse", sem entrar no mérito de que "aquilo que se disse" pode não corresponder ao factível. "Este movimento representa uma mudança potencialmente radical na forma como o jornalismo é praticado" (NYHAN, REIFLER, 2013 apud DOURADO, 2016, p.3). O jornalismo declaratório é considerado um "vício" da profissão do jornalista para José Roberto de Toledo ${ }^{12}$, em declaração no documentário O Mercado de Notícias (2014):

Em todo lugar, mas em Brasília principalmente, temos um vício, o que chamamos de jornalismo declaratório: alguém falou alguma coisa. É muito cômodo o jornalismo declaratório, porque [você pode argumentar ao dizer] "mas fulano que falou" e sempre que isso entrar em conflito com os fatos objetivos você fala, "mas fulano falou". (O MERCADO..., 2014).

\section{Modelo econômico de sustentabilidade}

Além da descrição do processo que caracterizou o trabalho de checagem de informação da Pública, considera-se importante discorrer nesta pesquisa sobre o modelo econômico adotado pela agência para sua sustentabilidade, com o intuito de somar à compreensão do que possibilitou o desenvolvimento de um projeto de fact-checking como o Truco!, além de obter indícios de sua credibilidade. O

\footnotetext{
${ }_{12}$ No momento de sua participação no documentário o jornalista José Roberto de Toledo escrevia uma coluna semanal sobre política em seu blog no Estadão, coordenava o Estadão Dados, era vicepresidente da Associação Brasileira de Jornalismo Investigativo (Abraji).
} 
financiamento do veículo está atrelado a um formato independente de atuação, o que corresponde a não estar vinculado a um modelo comercial para sua manutenção.

A sustentabilidade da agência acontece a partir da contribuição financeira de seus parceiros, segundo o site da Pública $^{13}$. No período que interessa para este trabalho de pesquisa, o ano de 2014, a agência contava como financiadora a Fundação Ford, a partir de seu programa de Direito e Acesso à Mídia, segundo Maurício Moraes (informação verbal) ${ }^{14}$. Abaixo, comenta-se brevemente sobre a instituição a fim de apresentá-la, porém sem a pretensão de analisá-la ou esgotar as informações sobre a organização.

Sediada em Nova York (EUA), a Fundação Ford tem como objetivo principal de seu trabalho ações que visam a promoção da democracia e a redução da pobreza. No Brasil, fomenta projetos nas linhas de direitos humanos, desenvolvimento sustentável, educação e liberdade de expressão. O professor e pesquisador na área de comunicação política Mauro Porto chegou a atuar como assessor da área "Mídia e liberdade de expressão" da Fundação Ford no Brasil ${ }^{15}$.

Além da Pública, outros beneficiados da instituição, levantados em artigo da revista do Programa de Pós-Graduação em Ciência da Informação da Universidade Federal do Ceará ${ }^{16}$, são: Intervozes - Coletivo Brasil de Comunicação Social, Universidade de Brasília (UnB), Fórum Nacional pela Democratização da Comunicação, Instituto Patrícia Galvão, Instituto Brasileiro de Defesa do Consumidor (Idec), Centro Cultural Luiz Freire, Observatório da Imprensa, Cipó: Comunicação Interativa, Associação Artigo 19 e Fundação Getúlio Vargas (FGV).

Em relação ao Truco! o recurso financeiro que possibilitou o projeto não adveio especificamente para sua realização, mas de um aporte feito pela Fundação Ford para a manutenção da Agência Pública como um todo. A contrapartida exigida pela instituição foi um relatório de prestação de contas das atividades desempenhadas em 2014 e do valor destinado a cada uma delas. Segundo Maurício Moraes (informação verbal) ${ }^{17}$, não houve direcionamento editorial para o desenvolvimento da iniciativa de checagem ou interferência no conteúdo produzido pela Pública.

Também, não foram identificadas propagandas da Fundação Ford ou outro financiador na página na internet da Pública ou em suas postagens na página da agência na rede social Facebook. Apenas na seção Quem somos de seu site, está

\footnotetext{
${ }^{13}$ Disponível em: apublica.org/quem-somos/\#financiadores. Acesso em: 21 jun. 2017.

14 Informação mencionada por Maurício Moraes durante entrevista telefônica para o desenvolvimento desta pesquisa, em São Paulo-SP, em dezembro de 2017.

15 Disponível em: basessibi.c3sl.ufpr.br/brapci/index.php/article/download_view/51951. Acesso em: 19 out. 2017.

16 Idem.

17 Informação mencionada por Maurício Moraes durante entrevista telefônica para o desenvolvimento desta pesquisa, em São Paulo-SP, em dezembro de 2017.
} 
presente um espaço indicando Financiadores ${ }^{18}$. Ainda de acordo com Maurício, tratase de deixar explícito quem são as organizações que viabilizam a manutenção da agência como uma postura de transparência junto ao público.

Para uma das diretoras e idealizadora da Agência Pública, Natalia Viana, o jornalismo investigativo praticado pelo veículo "é um tipo de jornalismo fundamental para a democracia, mas que não vai trazer resultado financeiro. Precisa ser incentivado de alguma maneira" (informação verbal) ${ }^{19}$, já que a sobrevivência de um veículo por meio do modelo comercial exige proximidade de empresas que compram espaço publicitário para alavancar seus negócios. O que, a depender de como administrada a relação, poderia causar conflitos de interesses e prejudicar o jornalismo de qualidade ${ }^{20}$.

Se por um lado o desenvolvimento da indústria midiática possibilitou a produção e difusão de formas simbólicas de maneira generalizada, pela exploração comercial das inovações técnicas (THOMPSON, 2001), por outro a busca por aumentar a audiência nesse meio competitivo impactaria negativamente a produção de informação (GOMES, 2005b). O problema conforme Gomes (2005b, p.62), em análise sobre veículos tradicionais da imprensa, é que há características desses meios de comunicação que "atingem diretamente as condições culturais e cognitivas da participação política” da população:

A forte concorrência interna entre as indústrias de informação e, neste contexto, o imperativo de atendimento às necessidades do mercado de notícias e entretenimento levaram a comunicação de massa a assumir características que, numa lista aleatória, vão do sensacionalismo à simplificação das questões e informações políticas segundo interesses de competição e consumo a distorções, voluntárias ou involuntárias, em virtude de a pauta política estar orientada pelos imperativos de venda. (GOMES, 2005b, p.62-63).

Por isso, um dos aspectos em discussões entre os projetos de fact-checking mundialmente é a preocupação com o financiamento das iniciativas, que estão em processo de descoberta de possibilidades de modelos compatíveis com seus objetivos. No geral, as plataformas de checagem de informação acreditam na necessidade de diversificar suas fontes de sustento, para tentarem garantir a manutenção do trabalho, como a partir da utilização de campanhas de financiamento coletivo $^{21}$ que já começaram a ser realizadas (MANTZARLIS, 2015).

\footnotetext{
${ }_{18}$ Disponível em: apublica.org/quem-somos/\#financiadores. Acesso em: 9 dez. 2017.

${ }_{19}$ Comentário realizado por Natalia Viana durante entrevista presencial para o desenvolvimento de notícia do jornal da Associação Brasileira de Imprensa (ABI), em São Paulo-SP, em janeiro de 2012.

${ }^{20}$ Para obter mais informações consultar "O Capital com 'pressa' e o jornalista sem fonte" (FELIX, 2010).

${ }^{21}$ Também denominadas campanhas de crowdfunding, trata-se da arrecadação de fundos junto à população interessada para a realização de projetos.
} 
Ao tratar de novas organizações ciberculturais que trabalham com jornalismo, Saad (2011 apud SANTOS, 2014, p.144) menciona como exemplos: Wikileaks, ProPublica, Polico.com, GlobalVoices, IDL-Reporters e as brasileiras Agência Pública, Repórter Brasil, Transparência Brasil e Contas Abertas. Isso para classificá-las como envolvidas em ações colaborativas que contemplam atividades em conjunto com o público geral, mas também para caracterizar essas iniciativas como detentoras de independência editorial em relação às empresas jornalísticas tradicionais; também, ressalta que utilizam intensamente as tecnologia da informação e sistemas de banco de dados para a mineração e correlação do conteúdo; e que contam com novas formas de sustentação financeira para produzir informação, como doações e mecenato.

\section{Avaliação da checagem de informação}

Os critérios da Pública para elencar as frases do horário eleitoral na televisão a serem checadas se concentraram em três: quando os candidatos à presidência mencionavam dados numéricos, porque seria possível comparar com dados já existentes e disponíveis; além de afirmações consideradas categóricas, em que a equipe observava a existência de palavras ou ideias determinantes; e ainda quando a frase do político fizesse menção suspeita de ser um perigo à democracia ou aos direitos humanos.

Para tangibilizar os discursos que traziam palavras ou ideias determinantes, passíveis de serem classificados como categóricos, identificou-se a presença dos seguintes termos nas falas dos políticos: "a maior de todos os tempos", "todo ano", "casamento é homem e mulher", "[a candidatura governista] que fracassou", "assumimos a vanguarda mundial", "o crescimento do PIB esse ano: é nada", "têm a melhor educação", "aprovamos o Plano Nacional de Educação", "acabou com o elitismo", "garantimos um bônus" e outros nessa perspectiva, extraídos do corpus de análise.

Como exemplo, pode ser mencionada a seguinte frase de Aécio Neves, no programa 1, de 19 de agosto: "Problemas que já tinham sido superados estão agora voltando. A inflação já está aí de novo, batendo na sua porta, entrando na sua casa"22. Mesmo a declaração não contendo dados numéricos para comparação, o candidato defende que a inflação voltou como um acontecimento definitivo. A Pública pondera sobre o discurso ao se basear em indicativos do campo da economia, e relata que "a inflação tem se mantido dentro da meta definida pelo Banco Central desde 2004" 23 .

22 Disponível em: apublica.org/truco-programa-1/. Acesso em: 17 abr. 2017.

${ }^{23}$ Idem. 
Também, traz um histórico dos números da inflação nos dois mandatos do governo Lula (2003-2010) e nos dois de Fernando Henrique Cardoso (1995-2002) para comparação.

Ao analisar as falas checadas pela Pública a partir do indicador Critérios, pode-se entender que a agência cumpriu com o proposto inicialmente em seu projeto, conforme dados da primeira coluna da tabela 1, adiante. Do total de 98 discursos, $45 \%$ trouxeram números ou dados; $51 \%$ puderam ser classificados como falas categóricas; $3 \%$ estavam relacionados ao perigo à democracia ou direitos humanos; e apenas $1 \%$ - o que correspondeu a uma frase - poderia ser classificado como fora dos critérios, o que torna esse item menos relevante diante da assertividade do trabalho como um todo.

Já em relação ao indicador Recursos, com os dados localizados na segunda coluna da tabela a seguir, em cada edição publicada do Truco!, a Pública não apenas dava seu veredicto sobre os discursos, mas produzia um texto curto argumentando o porquê ter classificado a frase com determinada carta do baralho, como já demonstrado na imagem 2 , neste artigo. O conteúdo primou pela objetividade, mas sem perder o aprofundamento do fato ou tema tratado, além de dar o crédito das fontes e indicar links para interessados em saber mais do assunto - construção no formato de hipertexto ${ }^{24}$.

Tabela 1 - Sistematização da checagem de informação

\begin{tabular}{|l|r|r|l|r|r|l|r|r|}
\hline \multicolumn{2}{|c|}{ Critérios } & \multicolumn{3}{c|}{ Recursos } & \multicolumn{3}{c|}{ Coerência } \\
\hline Números ou dados & 44 & $45 \%$ & Pesquisa & 8 & $5 \%$ & Pertinente & 91 & $93 \%$ \\
\hline Fala categórica & 50 & $51 \%$ & Fatos históricos & 3 & $2 \%$ & Parcialmente & 6 & $6 \%$ \\
\hline $\begin{array}{l}\text { Perigo à democracia } \\
\text { ou direitos humanos }\end{array}$ & 3 & $3 \%$ & Dados oficiais & 74 & $48 \%$ & pertinente & 1 & $1 \%$ \\
\hline Não pertinente & 1 & $1 \%$ & $\begin{array}{l}\text { Matéria } \\
\text { jornalística }\end{array}$ & 29 & $19 \%$ & & & \\
\hline & & & $\begin{array}{l}\text { Apuração com } \\
\text { fonte }\end{array}$ & 36 & $23 \%$ & & & \\
\hline & & $\begin{array}{l}\text { Não } \\
\text { fundamentado }\end{array}$ & 4 & $3 \%$ & & & \\
\hline & 98 & $100 \%$ & Total & 154 & $100 \%$ & Total & 98 & $100 \%$ \\
\hline
\end{tabular}

Fonte: autora

Das 98 checagens, em $48 \%$ foram utilizados como recurso dados oficiais; em 23\% ocorreu apuração com fonte; em $19 \%$ o uso de matérias jornalísticas; $5 \%$ mencionaram pesquisas; $2 \%$ trouxeram fatos históricos; enquanto $3 \%$ apareceram como não fundamentado. Assim, os dados revelam que houve preocupação quase permanente da Pública com o embasamento de suas checagens, demonstrando que

${ }^{24}$ Formato textual na internet que permite a indexação de conteúdo externo ao texto por meio de links. 
há argumentação no trabalho de pesquisa do Truco! o que possibilitou ao eleitor confiar nas informações expostas.

Considerou-se para dados oficiais documentos e definições em sites de instituições do poder público; para apuração com fonte, o retorno de assessoria de imprensa, além de informações, pareceres técnicos ou anuários de órgãos conceituados da sociedade civil, e artigos de colunistas; já matéria jornalística correspondeu às notícias linkadas na argumentação; pesquisa abarcou tanto artigos acadêmicos como pesquisas do Serasa ${ }^{25}$ ou Data Popular ${ }^{26}$; e por fim, fatos históricos corresponderam às citações de acontecimentos não validados por um dado numérico, mas que se tratou da descrição de um fato ocorrido.

Também é interessante notar que ao produzir um texto argumentativo que justificasse a classificação das cartas, era revelada conjuntamente a origem dos dados utilizados pela Pública para confrontar as declarações políticas, que neste trabalho foi chamado de recursos. Porém, como origem dos dados não se pode tomar apenas o fato de citar a fonte em que a agência se embasou para realizar a checagem, mas além disso, disponibilizar um link ou material on-line com informações que comprovavam o contraponto ou a reiteração da agência em relação às falas dos presidenciáveis. A atividade é inovadora, pois possibilitou que aqueles que tivessem acesso à plataforma pudessem contar com provas de que a checagem de informação estava embasada.

A agência não apenas classificar os discursos dos presidenciáveis, mas também demonstrar qual a base de sua justificativa, é uma característica dos projetos de fact-checking. A ideia é a de que o leitor também possa verificar o trabalho realizado por esse tipo de prática, assim como os checadores fazem com as falas dos políticos, indicando a fonte primária dos dados (NEISSER, 2015). Como a transparência na divulgação de informações é ponto central do projeto, também se colocam como passíveis de erros e, portanto, na condição de terem seu trabalho averiguado.

Além disso, e principalmente, a partir das argumentações da Pública e disponibilização dos materiais on-line, o eleitor passou a contar, por meio da checagem na internet, com uma gama de conteúdos políticos relacionados aos assuntos abordados pelos presidenciáveis durante o HGPE na TV, possibilitando-o estar mais bem informado ao ampliar a compreensão em relação às questões políticas.

Ainda que os veículos tradicionais da imprensa também estejam presentes na internet e detenham grande parte da audiência, Ramonet (2013) alerta para a diferença de que no meio digital há condições de intervenção de outros atores,

\footnotetext{
${ }^{25}$ Empresa privada que reúne um cadastro de empresas e indivíduos em situação de dívida.

${ }^{26}$ Instituto de pesquisa, realiza levantamentos nacionais.
} 
abrindo a possibilidade para a realização da mídia independente nos moldes da Agência Pública. Então, há potencialidade para alcançar pessoas que "terão acesso à informação com função de contrainformação ou de correção" (RAMONET, 2013, p.96). Há ampliação das opções pelas quais se pode adquirir conteúdo.

Neste contexto, ressaltam-se as modificações na relação entre a tecnologia e os processos comunicacionais sociais, já que as redes digitais "incorporam facilmente novos discursos, novos formatos de sites, novas plataformas e novas criações" (SILVEIRA, 2009, p.84). Assim, com o surgimento da internet, apresenta-se também a constituição de uma nova dimensão política a partir da era da intercomunicação (CASTELLS, 2006 apud LEMOS; LEVY, 2010).

Ainda, cabe ressaltar que em cada checagem, mais de um recurso para argumentação pôde ser utilizado, o que ocorreu com frequência, já que puderam ser contabilizados 154 recursos no total das averiguações, sendo que o total de discursos checados era 98 , como demonstrado na tabela 1 . O número reforça o trabalho de pesquisa da equipe do Truco!, pois considerou diversificar os tipos de recursos em suas justificativas, apoiando-se em mais de uma fonte para construir cada uma das 98 argumentações.

Com relação à porcentagem de argumento não fundamentado (3\%), ocorreu quando alguma pontuação foi realizada dentro dos textos divulgados pela Pública e não ficou clara a origem da informação. Seria desejável que em todas as menções fossem indicadas a sua fundamentação. Apesar disso, essa classificação "não fundamentado" não apareceu sozinha em nenhuma das 98 matérias analisadas. Em um mesmo texto em que foi citada alguma informação sem esclarecimento do crédito, havia também outros recursos que trouxeram sustentação aos argumentos centrais utilizados pela Pública.

A partir do último indicador, denominado Coerência, com os dados na terceira coluna da tabela 1, disposta anteriormente, compara-se o veredicto da Pública (carta do baralho e seu significado) sobre os discursos dos candidatos com a argumentação contida no texto. Dito de outra forma, foi avaliado se o diagnóstico final explicitado por meio das cartas do baralho estava coerente com o texto produzido pela Pública para justificar a classificação.

Em 93\% dos casos checados, a classificação foi pertinente; em 6\%, parcialmente pertinente; enquanto $1 \%$ - o que correspondeu a um caso - entrou na categorização como não pertinente. Adotou-se para pertinente quando o texto argumentativo da Pública para justificar a carta escolhida correspondia ao significado da carta. Parcialmente quando havia informações para classificar o discurso com outro tipo de carta, constatando que em alguns momentos a linha pode ser tênue entre uma e outra carta (classificação). Além de não pertinente ocorreu no caso em que a justificativa utilizada no texto pareceu não corresponder ao significado da carta escolhida. 
Com relação às duas últimas classificações - parcialmente e não pertinente aconteceram principalmente por divergência das pesquisadoras deste estudo com relação a determinar discursos com a carta Não é bem assim, mesmo havendo elementos suficientes para o veredicto Blefe! O que pode indicar que a Pública adotou extrema cautela na utilização dessa última carta, já que ela correspondia a taxar a declaração como mentirosa. Além de confusão na utilização das cartas Não é bem assim e Tá certo, mas pera aí. Como ambas classificações significavam que os discursos políticos continham certa parte de veracidade, causou dúvidas na escolha da carta. E um último caso de uso da carta Zap! quando haveria justificativa suficiente para a adoção de Tá certo, mas pera aí.

As divergências parecem também chamar atenção para o fato de que apesar de a checagem de informação contar com um processo, não compõe uma prática totalmente lógica, em que o resultado é inquestionável. Quando os discursos contêm nuances de inverdades ou falta de contexto, pode ser mais difícil de enquadrar a declaração política em uma ou outra classificação. Nesses casos, parece prevalecer a interpretação de quem está produzindo a checagem, ainda que a prática tenha uma metodologia a seguir. Por outro lado, ressalta-se que casos assim ocorreram com menos frequência.

A partir dos resultados, pode-se refletir sobre o lugar do jornalismo na sociedade em rede e os projetos de fact-checking, nesse contexto, como capazes de distinguir informações qualificadas (BELDA; CARVALHO, 2017). Em meio ao dilúvio informacional, em que há dificuldades de localizar a credibilidade de quem produz e divulga conteúdos, bem como a constância de casos de fake news, a prática jornalística de apuração dos dados e checagem de informação, e a responsabilidade atrelada ao exercício da profissão do jornalista, configura um ambiente mais seguro para a obtenção de notícias críveis (BUCCI, 2017 apud SORRENTINO; SOUZA, 2017).

Nas eleições 2018 no Brasil, projetos de checagem de informação, incluindo o Truco!, verificaram discursos e entrevistas de políticos, mas estenderam suas verificações também para informações que estavam em evidência circulando pelas redes sociais. Dessa forma, puderam ser úteis ao identificarem algumas das fake news, estas que foram característica do pleito no país, realizando e divulgando seus contrapontos. Ter a mentira como estratégia política aliada à polarização transformou o país em um campo de batalha das mentiras. (FERNANDES; GIORDANI, 2019).

O trabalho de pesquisa de Fernandes e Giordani (2019) sobre as três principais agências de checagem brasileiras (Agência Pública, A Lupa e Aos Fatos) avaliou 286 checagens publicadas por elas no pleito mencionado. Notou-se que em sua maioria as averiguações tiveram como resultado a classificação de conteúdos enganosos, já que 200 do total das checagens continham a etiqueta falso. 


\section{Desirèe Luise Lopes Conceição e Rosemary Segurado}

A checagem de informação confronta os discursos políticos diante de um público ampliado. Publicizadas na internet, as verificações estão acessíveis e quanto mais circular, alcançando maior número de pessoas, mais repercussão o fato terá (DOURADO, 2016). Porém, se por um lado a prática pode ajudar a provocar um processo de accountability, ao impactar na imagem do candidato junto aos seus possíveis eleitores ou levantar o debate sobre algum fato político, por outro "não quer dizer que o político vai sofrer alguma sanção apenas pela desconstrução do seu discurso" (DOURADO, 2016, p.18).

Também, apesar de a mídia adicionar esforços para criar uma sociedade mais vigilante e crítica (MAIA, 2006), o acesso à informação política não torna os indivíduos automaticamente cidadãos mais informados e ativos (GOMES, 2005a). Maia (2006) já discorria sobre a dificuldade de mensurar o impacto da prática comunicativa no público. Trata-se de um dilema não apenas de projetos de fact-checking, mas da prática jornalística como um todo. "É difícil apreender os efeitos da cobertura midiática de tais iniciativas e mobilizações cívicas. Para captar tais efeitos, seria preciso conduzir uma pesquisa específica” (MAIA, 2006, p.20).

\section{Considerações finais}

A partir dos resultados, pode-se concluir que a prática do fact-checking da Pública demonstra ser bem desenvolvida, já que há altos índices de coerência e nulidade nas publicações realizadas por meio do projeto Truco! Além da criatividade da estrutura semelhante a um jogo de cartas, sua singularidade está na construção de um processo de validação das declarações dos candidatos, ademais na produção de um conteúdo específico e exclusivo, por meio dos textos argumentativos que acompanhavam a checagem, que circulou livremente sobre assuntos abordados nas campanhas eleitorais na televisão em 2014.

Com a checagem de informação e construção dos textos explicativos sobre os veredictos em relação aos discursos, a agência ampliou o conteúdo presente nas declarações. Além de disponibilizar materiais sobre as temáticas surgidas no HGPE com a divulgação de links, também concomitantemente prestou contas de suas argumentações ao apontar as fontes utilizadas para a checagem por meio desses mesmos links. Com isso, a Pública propiciou o surgimento de mais elementos informativos em período eleitoral.

Portanto, projetos de checagem de informação podem ser mais uma ferramenta, dentre outras, com a qual os eleitores e a população em geral podem contar para adquirir conteúdo político embasado. A desinformação, que se desenvolve em um campo onde não há espaço para contraposições (DEBORD, 1997), passa a contar com iniciativas como a da prática do fact-checking atuando na contramão. 
Há, ainda, a possibilidade de realçar um novo fenômeno com o qual a checagem de informação já tem lidado, o do crescimento dos casos de fake news. As notícias falsas contam com a peculiaridade de estarem inseridas nas dinâmicas das redes digitais e a partir das técnicas jornalísticas de apuração dos fatos, pode-se refletir sobre a checagem de informação, agora não só de discursos dos políticos, mas também de declarações públicas em geral, como uma das ferramentas para fazer frente às fake news. Ao identificarem informações falsas, se baseando nos fatos, e divulgarem o contraponto, projetos de checagem podem ser um instrumento a contribuir positivamente.

Apesar disso, ressalta-se que o trabalho realizado pelos projetos de checagem de informação não apresenta o que é a verdade em um sentido estrito. "Diante de uma palavra de difícil determinação, com significado fluído, um caminho mais seguro seria o de deslocar a preocupação de avaliar se o discurso político é verdadeiro para se as declarações contêm fundamentos concretos em acontecimentos" (CONCEIÇÃO, 2018b, p.27). Assim, o fact-checking ajudaria mais a desmistificar informações inverídicas que se passam por verdades, do que estabelecer verdades absolutas por meio da verificação das informações (CONCEIÇÃO, 2018a).

Também cabe mencionar que tanto em relação à prática para a construção de notícias como para desenvolver ofact-checking não se pode pressupor a existência da neutralidade da informação. Segundo a Teoria Construcionista, o produto do jornalismo não é um reflexo estrito da realidade, mas sim mais um elemento que ajudará na construção social (QUINDERÉ, 2007 apud CONCEIÇÃO, 2018b).

Assim, o resultado do trabalho do jornalista não poderia configurar-se como um espelho do real ao admitir-se que o profissional realiza a atividade jornalística a partir de uma atuação "interativa, dependendo tanto das rotinas produtivas e das escolhas dos jornalistas como também de demandas sociais, econômicas, culturais e históricas" (QUINDERÉ, 2007, p.7 apud CONCEIÇÃO, 2018b, p.20). Os construcionistas apontam que "o jornalismo encontra referencial na realidade, mas esta é apresentada em uma notícia a partir de determinados enquadramentos" (CONCEIÇÃO, 2018b, p.21), conferindo poder ao campo dos mídia ${ }^{27}$.

Por fim, com a problematização dos assuntos abordados durante as propagandas eleitorais na televisão, durante a eleição de 2014, que pode ser recordada por sua extrema polarização no plano presidencial entre Partido dos Trabalhadores (PT) e Partido da Social Democracia Brasileira (PSDB), e a construção de um espaço de contrainformação em relação às declarações dos

\footnotetext{
${ }^{27}$ Adota-se para a definição o que Maia (2002) chama de campo dos mídia: um campo de instituição social da mesma forma que o religioso, o político, o científico, o militar, o econômico. A autora cita Adriano Rodrigues (1990) para concordar que "a função básica deste campo seria conferir visibilidade pública às questões coletivas da vida social, mediar e dar expressão aos atores provenientes dos demais campos, promovendo a inserção desses na cena pública" (MAIA, 2002, p.3).
} 
políticos, contribui-se para a qualidade da comunicação ao favorecer a transparência da informação no espaço público.

\title{
FACT-CHECKING: AN ANALYSIS OF THE POLITICAL INFORMATION VERIFIED BY THE TRUCO! PROJECT
}

\begin{abstract}
This article aims to analyze the political information produced and disseminated by the digital platform Truco!, which is a Agência Pública fact-checking project developed for the 2014 election, in Brazil. This project, one of the first in the country, verified the presidential candidates' speeches during the free electoral campaign advertising on television comparing what they said with data and the facts available. The methodology consists of an elaboration for primary data collection, defined upon initial observation of the Agência Pública work. The results recognize qualitative investigative journalism work, showing a process to practice the fact-checking, and the broadening of the political content. Therefore, a counter-information space was built, with the possibility of using the fact-checking to face a recent global phenomenon, the fake news cases.
\end{abstract}

KEYWORDS: Internet. Political speech. Information. Cyber-politics. Fact-checking.

\section{FACT-CHECKING: UN ANÁLISIS DE VERIFICACIÓN DE INFORMACIÓN POLÍTICA DEL PROYECTO TRUCO!}

RESUMEN: El artículo tiene como objetivo analizar la producción y difusión de información política en la plataforma digital "Truco!", un proyecto de verificación de información - de la Agência Pública desarrollado para las elecciones de 2014. La iniciativa, una de las pioneras en el Brasil, levantó los discursos de los candidatos presidenciales en la Hora Libre de Propaganda Electoral (HGPE) en la televisión y verificó las declaraciones comparándolas con los datos disponibles. La conclusión de la verificación, publicada en Internet, reveló si las declaraciones contenían información correcta, sin contexto, distorsionada o falsa. La metodología consistió en la elaboración de indicadores para la reunión de datos primarios y entrevistas individuales. Los resultados permiten identificar un trabajo de periodismo de investigación de calidad, revelando un proceso de comprobación y ampliación del contenido político de los temas que surgieron en el HGPE. Así, se construyó un espacio de contrainformación, con la posibilidad de pensar en la práctica de revisar para enfrentar un fenómeno reciente, los casos de noticias falsas.

PALABRAS CLAVE: Internet. Discurso politico. Ciberpolitica. Fact-checking. Comprobación de información. 


\section{REFERÊNCIAS}

AVELAR, Daniel. WhatsApp fake news during Brazil election 'favoured Bolsonaro'. The Guardian, 30 oct. 2019. Disponível em https:/www.theguardian.com/world/2019/oct/30/ whatsapp-fake-news-brazil-election-favoured-jair-bolsonaro-analysis-suggests. Acesso em: 22 jun. 2020.

BELDA, Francisco Rolsfen. \& CARVALHO, Pedro Henrique Varoni. Multiparcialidade, dialogia e cultura participativa como reação a pós-verdade. Culturas Midiáticas. Revista do Programa de Pós-graduação em Comunicação da Universidade Federal da Paraíba, v. 10 n. 18, p.230-245. Janeiro/Junho 2017. Disponível em: https://periodicos.ufpb.br/index.php/ cm/article/view/35045/17899. Acesso em: 23 jun. 2020.

CARVALHO, Fernanda Cavassana; CERVI, Emerson Urizzi; MASSUCHIN, Michele Goulart (orgs). Internet e eleições no Brasil. Curitiba: Grupo de pesquisa em Comunicação Política e Opinião Pública, 2016. Disponível em: www.academia.edu/30246524/2016 Internet_e_elei\%C3\%A7\%C3\%B5es_no_Brasil. Acesso em: 18 nov. 2017.

CIOCCARI, Deysi; COELHO, Cláudio Novaes Pinto. EZEQUIEL, Vanderlei de Castro. O pensamento conservador e as manifestações de ódio na cena política brasileira. Revista Estudos de Sociologia. Araraquara, v. 24, no 46, p.267-286, jan-jun/2019. Disponível em: https://periodicos.fclar.unesp.br/estudos/article/view/9539. Acesso em: 22 jun. 2020.

CONCEIÇÃO, Desirèe Luíse Lopes. Fact-checking e fake news: a checagem de informação como confrontação às notícias falsas. Horizontes ao Sul. Postado em 7 agosto 2018a. Disponível em www.horizontesaosul.com/single-post/2018/08/07/FACT-CHECKINGE-FAKE-NEWS-A-CHECAGEM-DE-INFORMA\%C3\%87\%C3\%83O-COMOCONFRONTA $\%$ C3\%87\%C3\%83O- $\%$ C3\%80S-NOT\%C3\%8DCIAS-FALSAS. Acesso em: 22 jun. 2020.

CONCEIÇÃO, Desirèe Luíse Lopes. Internet e cidadania: o estímulo ao debate político por meio do jornalismo fact-checking - Um estudo de caso do projeto "Truco!". Orientadora: Rosemary Segurado. 2018b. Dissertação (Mestrado em Ciências Sociais), Programa de Estudos Pós-graduados em Ciências Sociais, Pontifícia Universidade Católica de São Paulo, São Paulo, 2018.

DEBORD, Guy. A sociedade do espetáculo: Comentários sobre a sociedade do espetáculo. Rio de Janeiro: Contraponto, 1997.

DOURADO, Tatiana. Fact-checking como possibilidade de accountability do jornalismo sobre o discurso político: as três iniciativas brasileiras. Paper apresentado no $\mathbf{4 0}^{\circ}$ Encontro Anual da ANPOCS. Caxambu, 2016. 


\section{Desirèe Luise Lopes Conceição e Rosemary Segurado}

FELIX, Jorge. O capital com pressa e o jornalista sem fonte. In: MARQUES, Rosa Maria; JANSEN, Mariana (orgs). O Brasil Sobre a Nova Ordem - A economia brasileira contemporânea. 1.ed. São Paulo: Saraiva, 2010.

FERNANDES, Márcio; GIORDANI, Renatha. As agências de Fact-Checking frente às eleições de 2018. Intercom - Sociedade Brasileira de Estudos Interdisciplinares da Comunicação XX Congresso de Ciências da Comunicação na Região Sul - Porto AlegreRS - 20 a 22/06/2019. Disponível em: http://portalintercom.org.br/anais/sul2019/resumos/ R65-0613-1.pdf. Acesso em: 10 abr. 2020.

GOMES, Wilson. A democracia digital e o problema da participação civil na decisão política. Revista Fronteiras - estudos midiáticos. São Leopoldo, v. VII, nº 3, p.214-222, setembro/ novembro 2005a.

GOMES, Wilson. Internet e participação política em sociedades democráticas. Revista Famecos. Porto Alegre, $n^{\circ}$ 27, p.58-78, agosto 2005b.

LEMOS, André. \& LÉVY, Pierre. O futuro da internet: em direção a uma ciberdemocracia planetária. São Paulo: Paulus, 2010.

MAIA, Rousiley Celi Moreira. Mídia e diferentes dimensões da accountability. E-compós. Brasília, v. 6, n 3, p.1-27, dezembro 2006.

MAIA, Rousiley Celi Moreira. Mídia e deliberação pública: mediações possíveis. Paper apresentado no XI Encontro Anual da Compós. Brasília, 2002.

MANTZARLIS, Alexios. In Buenos Aires, fact-checkers plan a code of principles and an International Fact-Checking Day. Poynter. June 12, 2016. Disponível em: www.poynter.org/ news/buenos-aires-fact-checkers-plan-code-principles-and-international-fact-checking-day. Acesso em: 22 jun. 2020.

MANTZARLIS, Alexios. Introducing Poynter's International Fact-checking Network. Poynter. October 21, 2015. Disponível em: https://www.poynter.org/fact-checking/2015/ fact-checkers-of-the-world-unite/. Acesso em: 23 jun. 2020.

MELLO, Patrícia Campos. WhatsApp admite envio maciço ilegal de mensagens nas eleições de 2018. FOLHA DE S.PAULO, 8 de outubro de 2019. Disponível em https:/www1.folha. uol.com.br/poder/2019/10/whatsapp-admite-envio-massivo-ilegal-de-mensagens-naseleicoes-de-2018.shtml. Acesso em: 22 jun. 2020.

NEISSER, Fernando Gaspar. Fact-checking e o controle da propaganda eleitoral. Revista Ballot. Rio de Janeiro, V.1, nº 2, p.178-212, Set/Dez 2015.

O MERCADO de notícias. Direção: Jorge Furtado. Documentário Produzido por Nora Goulart. Casa de Cinema de Porto Alegre, 2014. Disponível em: https://www.youtube.com/ watch?v=zq4CpvHdbAA\&t=2s. Acesso em: 6 ago. 2017. 
POYNTER. Commit to transparency - sign up for the International Fact-Checking Network's code of principles. Disponível em www.poynter.org/fact-checkers-code-of-principles/. Acesso em: 15 mai. 2017.

RAMONET, Ignacio. A explosão do jornalismo na era digital. In: MORAES, D; RAMONET, I; SERRANO, P. Mídia, Poder e Contrapoder, da concentração monopólica à democratização da informação. São Paulo: Boitempo, 2013.

SANTOS, Carlos Eduardo Sandano. Para além do código digital: Discussões epistemológicas para a prática jornalística na contemporaneidade. Orientadora: Cremilda Medina. 2014. Tese (Doutorado em Ciências da Comunicação), Programa de Pós-graduação em Ciências da Comunicação da Escola de Comunicação e Artes, Universidade de São Paulo, São Paulo, 2014.

SILVEIRA, Sérgio Amadeu da. Esfera pública interconectada, blogosfera e redes sociais. In: COELHO, C. N. P. Esfera Pública, Redes e Jornalismo. Rio de Janeiro: e-papers, 2009.

SORRENTINO, Tainã Ribeiro \& SOUZA, Rogério Martins. Jornalismo e pós-verdade: uma análise das notícias falsas divulgadas por Donald Trump. Paper apresentado no XXII Congresso de Ciências da Comunicação na Região Sudeste. Volta Redonda, 2017.

STENCEL, Mark. Number of fact-checking outlets surges to 188 in more than 60 countries. Duke Reporters LAB. 11 june 2019. Disponível em: reporterslab.org/number-of-factchecking-outlets-surges-to-188-in-more-than-60-countries/. Acesso em: 22 jun. 2020.

THOMPSON, John Brookshire. A mídia e a modernidade: uma teoria social da mídia. Petrópolis: Vozes, 2001.

Recebido em 12/11/2019.

Aprovado em 06/05/2020. 
